\title{
Hybrid identification for Glycine max and Glycine soja with SSR markers and analysis of salt tolerance
}

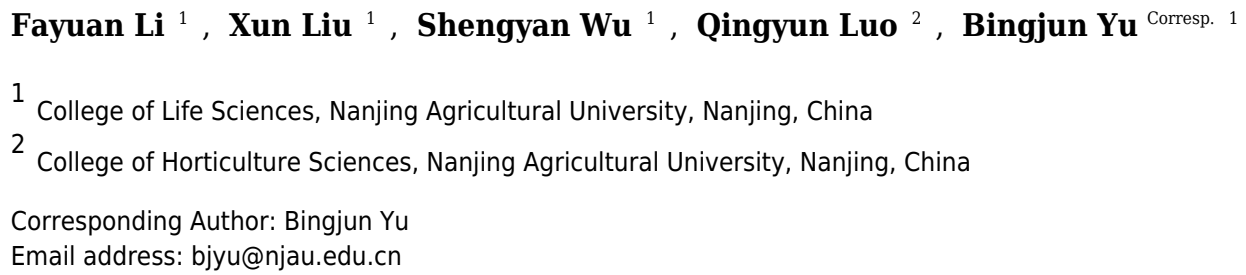

Glycine max cultivars Lee68, Nannong1138-2, Nannong8831 were used as the female parents, and hybrid lines $\left(F_{5}\right) 4111,4076$ [N23674 × BB52], 3060 [Lee68 × N23227] and 185 [Jackson $\times$ BB52] that selected for salt tolerance generation by generation from the cross combination of $G$. max and G. soja were used as the male parents, 11 (A-K) backcrosses or three-way crosses were designed and 213 single hybrids were harvested. The optimized soybean SSR-PCR system was used to analyze the SSR polymorphism of above parental lines and get the parental co-dominant SSR markers for hybrid identification, and in which 30 true hybrids were gained. The true hybrids (G1, G3, G9, $\mathrm{G} 12, \mathrm{G} 13, \mathrm{G} 16$ ) of $\mathrm{G}$ cross combination were chosen as the representative for the salt tolerance test, and the results showed that, as exposed to salt stress, the seedlings of G9 line displayed higher salt tolerant coefficient, relative growth rate and dry matter accumulation, when compared with their female parent Nannong1138-2, and even performed equally strong salt tolerance as the male parent 3060. It provides a feasible method of the combination of molecular SSR markers and simple physiological parameters to identify the true hybrids of G. $\max$ and G. soja, and to innovate the salt-tolerant soybean germplasms. 
1 Hybrid identification for Glycine max and Glycine soja with SSR markers and analysis of 2 salt tolerance

3

4 Fayuan $\mathrm{Li}^{1 \dagger}$, XunLiu ${ }^{1 \dagger}$, Shengyan $\mathrm{Wu}^{1}$, Qingyun $\mathrm{Luo}^{2}$, Bingjun $\mathrm{Yu}^{1 *}$ 5

$6{ }^{1}$ College of Life Sciences, Nanjing Agricultural University, Nanjing 210095, P. R. China

$7{ }^{2}$ College of Horticulture Sciences, Nanjing Agricultural University, Nanjing 210095, P. R. 8 China

$9 \dagger$ These authors contributed equally to this work.

10

$11 *$ Corresponding Author:

12 Prof. Bingjun Yu

13 Email address: bjyu@njau.edu.cn

14

15

\section{ABSTRACT}

Glycine max cultivars Lee68, Nannong1138-2, Nannong8831 were used as the female parents, and hybrid lines $\left(\mathrm{F}_{5}\right)$ 4111, 4076 [N23674 × BB52], 3060 [Lee68 × N23227] and 185 [Jackson $\times$ BB52] that selected for salt tolerance generation by generation from the cross combination of G. $\max$ and $G$. soja were used as the male parents, 11 (A-K) backcrosses or three-way crosses were designed and 213 single hybrids were harvested. The optimized soybean SSR-PCR system was used to analyze the SSR polymorphism of above parental lines and get the parental co-dominant SSR markers for hybrid identification, and in which 30 true hybrids were gained. The true hybrids (G1, G3, G9, G12, G13, G16) of G cross combination were chosen as the representative for the salt tolerance test, and the results showed that, as exposed to salt stress, the seedlings of G9 line displayed higher salt tolerant coefficient, relative growth rate and dry matter accumulation, when compared with their female parent Nannong1138-2, and even performed equally strong salt tolerance as the male parent 3060. It provides a feasible method of the combination of molecular SSR markers and simple physiological parameters to identify the true hybrids of G. max and G. soja, and to innovate the salt-tolerant soybean germplasms.

\section{INTRODUCTION}


Salinity is one of the major abiotic stresses that adversely affect crop productivity and quality (Chinnusamy et al., 2005; Shrivastava et al., 2015). Approximately 22\% of the world's agricultural lands are affected by salinity (Bhatnagar-Mathur et al., 2008; Machado and Serralheiro 2017). It is reported that more than 800 million hectares of land throughout the world, which account for more than $6 \%$ of the world's total land areas, have been reported to be affected by salinity (Munns and Tester 2008). In China, there are about 36 million hectares saline lands. At present, what is worthy to be highly worried is that, the saline lands are expanding with the industry modernization, the increase of irrigated agrarian lands and greenhouse for vegetables and flowers in agriculture (Zhang et al., 2011). Therefore, the genetic improvement of crop salt tolerance, bioavailability and development of saline soil, has become the most important approaches in the future agriculture development.

Soybean is one of the main crops in China, and is also the main source of plant oil and protein in the world (Zhang et al., 2011; Adisa and Balogun 2013; Kim et al., 2017). It includes the cultivated soybean (Glycine $\max ($ L.) Merr.) and wild soybean (Glycine soja Sieb. \& Zucc.) G. soja is known as the ancestor of G. $\max$ (Hyten et al., 2006), and generally, G. soja is more salt tolerant than G. $\max$ (Luo et al., 2005; Patil et al., 2016). Although the cultivated soybean belongs to the moderate salt-tolerant plant (Tuyen et al., 2010), the great achievements in conventional breeding among G. max cultivars for improving its salt tolerance are difficult to obtain due to its narrowing basis of genetic germplasms and the relative limited salt tolerance, as well as the lower productivity and economic value in G. soja (Zhang et al., 2011). One of the effective ways to improve soybean salt tolerance and breed new soybean varieties is to select generation by generation for the hybrids with salt tolerance of heterosis from the cross combination of G. max and G. soja (Lee et al., 2004; Lee et al., 2009). The soybean hybrids with salt tolerance of heterosis often possess some adverse agronomic characters, such as plant climbing and vining, and small seeds, which can be improved by further backcrossing method to obtain the agricultural cultivars with specific individual target agronomic traits (Wang et al., 2003). However, the authenticity of hybrid identification is a very important process in the cross breeding of soybean cultivars. So an accurate, simple and fast method for identifying the soybean hybrid authenticity is urgently needed.

Molecular markers are powerful genomic tools for increasing the efficiency and precision of breeding practices for crop improvement (Ashraf et al. 2013). For example, SSR (simple 
62 sequence repeat, or microsatellite) markers are widely applied in molecular and genetic map 63 construction, genetic purity identification, genotype fingerprinting, analysis of germplasms 64 diversity and utilization of heterosis, which with some merits such as simplicity, quickness, rich 65 polymorphism, high stability and co-dominance (Burnham et al., 2002; Kuroda et al.,2009; Patil 66 et al., 2016). The polymorphic SSR markers, as an ideal molecular technology, has been used 67 widely to identify the variety identification or hybrid purity in rice, wheat, common bean, cotton, 68 rape, peanut, apple ,orange and psidium (Gaitán-Solís et al., 2002, Nandakumar et al., 2004; 69 Dawson et al.,2013; Tuler et al.,2015 ). The construction and optimization of the SSR reaction 70 system and the selection of SSR primers are the important foundation for its application. It was found for the rice cross-breeding that only one pair of primers would be sufficient to identify the hybrids, as long as the distinguished co-dominant SSR markers between the parents were screened clearly (Yashitola et al., 2002; Nandakumar et al., 2004). In this work, the hybrid lines $\left(\mathrm{F}_{5}\right)$ 4076, 4111, 3060 and 185 were used as the male parents, and the G. max cultivars Lee68, Nannong1138-2 and Nannong8831as the female parents, 11(A-K) backcrosses or three-way 76 crosses were designed and the harvested hybrids were identified by SSR markers. Then the salt tolerance of the true hybrid lines of one representative cross combination $(\mathrm{G})$ was evaluated as 78 79 80 compared with their parents. We aimed at providing an important theoretical principle for innovation of the salt tolerant soybean germplasms and improvement of salt tolerance in G. $\max$ by using $G$. soja.

\section{MATERIALS \& METHODS}

\section{Plant materials}

The hybrid lines $\left(\mathrm{F}_{5}\right)$ 4111, 4076, 3060 and 185 respectively selected and gained for salt tolerance generation by generation from the cross combination of G. max and G. soja [N23674 $\times$ BB52] (Zhang et al., 2011), [Lee68 × N23227] (Li et al., 2012) and [Jackson $\times$ BB52] (Wu et al., 2009), were used as the male parents, and the G. max cultivars Lee68 (the salt tolerant, USA), Nannong1138-2 and Nannong8831 (with fine agronomic traits, Nanjing, China) were used as the female parents, 11 combinations of backcross or three-way cross were designed (Table 1). The hybrid seeds of 12-28 plants (213 in total) of each combination were harvested individually after they ripened. The suitable amount of seed of each single plant was cultivated in the greenhouse for the next experiments.

\section{Total leaf DNA extraction}


93

94

95

96

97

98

99

100

101

102

103

104

105

106

107

108

109

110

111

112

113

114

115

116

117

118

119

120

121

122

123

Total genomic DNA was extracted from the young leaves of single plant seedling using CTAB (cetyltrimethylammonium bromide) method (Siew et al., 2018).

\section{PCR amplification and product electrophoresis}

All SSR-PCR reactions were performed on PCR system (Bio-Rad, Australia). PCR (polymerase chain reaction) was performed in a $10 \mu \mathrm{L}$ reaction volume, its reaction procedure is as follows: $94^{\circ} \mathrm{C}$ pre-denaturation $5 \mathrm{~min}, 94^{\circ} \mathrm{C}$ denaturation $30 \mathrm{~s}, 55^{\circ} \mathrm{C}$ annealing $40 \mathrm{~s}, 72^{\circ} \mathrm{C}$ extension $30 \mathrm{~s}, 30$ cycles; $72^{\circ} \mathrm{C}$ extension $10 \mathrm{~min}$, then $4^{\circ} \mathrm{C}$ insulation ( using the most suitable annealing temperature depending on the primer). Amplification products were analyzed by electrophoresis in $8.0 \%(\mathrm{w} / \mathrm{v})$ denaturing polyacrylamide gel in $1 \times \mathrm{TBE}$ buffer for $1 \mathrm{~h}$ on the DYY-6C electrophoresis apparatus (Beijing Liuyi Factory, China) under $220 \mathrm{~V}$ constant voltage. Fragments were then visualized by silver staining (Silver sequence staining reagents, Promega, USA) and sized with $50 \mathrm{bp}$ (base pairs) DNA ladder marker (TianGen Biotech Company, Beijing). SSR primer sequences (Table S1) were obtained from the soybean public databases (http://soybase.org/resources/ssr.php).

\section{SSR-PCR reaction system and screening polymorphic primers among parents of different} cross combinations

Using L16 $\left(4^{5}\right)$ orthogonal design (Yang et al., 2007), the exploration orthogonal test was performed at 5 factors (DNA template concentration, dNTP, primer concentration, Taq enzyme concentration and $\mathrm{Mg}^{2+}$ concentration) and 4 levels (Table S2). In addition to the table variables, each tube also contained $1.5 \mu \mathrm{L} 10 \times$ buffer, primer Satt242 and DNA template. Using the wellestablished best SSR-PCR reaction system, 24 pairs of primers of SSR markers were selected randomly on 20 linkage groups in soybean (Satt519, Satt467, Satt474, Sat-367, Sat-311, Satt432, Satt444, Satt168, Satt726, Satt161, Satt682, Satt-153, Satt-264, Satt556, Satt194, Satt-207, Satt286, Sat-332, Satt254, Satt147, Satt447, Satt-220, Satt708, Satt368, respectively) for PCR experiment in the genomic DNA of the experimental soybean materials to verify the stability of the obtained system. Then, the randomly selected 18 pairs of SSR primers (Satt682, Satt70, Satt368, Satt440, Sat-246, Sat-240, Sat-262, Satt649, Satt170, Satt242, Satt152, Satt102, Sat359, Sat-276, Sat-393, Satt530, Satt348, Satt072, respectively) to screen polymorphic primers between parents of different cross combinations, and the markers with clear and stable amplification type, polymorphism, obvious main band and less shadow tag were selected for the hybrid identification. 
124 Identification of true soybean backcross or three-way cross hybrid lines

125 Identification of true hybrids was performed as previously described (Nandakumar et al., 126 2004; Ben Romdhane et al., 2018). If the sample of hybrids containing two parental co-dominant

127 bands, could be judged as the true hybrid, otherwise could be false. One polymorphic SSR 128 marker (Satt682) was used in the current study to identify the two parents and 213 generated 129 hybrids (Table 2).

130 Determination of the salt tolerant coefficient

131 Salt tolerant coefficient was measured according to the method of Li et al. (2012). When the 132 first pair of unifoliolate leaf of true hybrid lines of cross combination G expanded fully, the 133 seedlings were treated with $50 \mathrm{mmol} / \mathrm{L} \mathrm{NaCl}$ solution (prepared with 1/2 Hoagland solution) for 1345 days, then increased by $25 \mathrm{mmol} / \mathrm{L} \mathrm{NaCl}$ solution every 5 days till its final concentration 135 increase to $150 \mathrm{mmol} / \mathrm{L}$. All the solutions listed above were replaced every 2 days. The number 136 of the plants appearing leaf salt injury symptom was recorded everyday until all the plants 137 appeared. Salt tolerant coefficient was calculated by the days when the leaf salt injury symptom 138 appeared on the 1 st plant, 50\% plants and 100\% plants, respectively.

139 Determination of the relative growth rate and dry matter accumulation

140 According to $\mathrm{Du}$ and $\mathrm{Yu}$ (2010), when the first pair of unifoliolate leaves expanded fully, the 141 seedlings were treated with 1/2 Hoagland solution (Control) and $120 \mathrm{mmol} / \mathrm{L} \mathrm{NaCl}$ solution 142 (prepared with 1/2 Hoagland solution) for 10 days. All the solutions listed above were replaced 143 every 2 days. Twelve young seedlings were sampled respectively for control and salt treatment, 144 and the plant height was measured. Relative growth rate $=[($ plant height after treatment - plant 145 height before treatment $) \div$ (plant height for control - plant height before treatment)] $\times 100 \%$. 146 Then the material was fully rinsed in distilled water, dried to constant weight at $80^{\circ} \mathrm{C}$ after $105^{\circ} \mathrm{C}$ 147 fixing for $10 \mathrm{~min}$. Dry matter accumulation $=$ (dry weight of salt-stressed single plant $\div$ dry 148 weight of control single plant) $\times 100 \%$

\section{RESULTS}

\section{DNA extraction and construction of soybean SSR-PCR reaction system}

The results of DNA extraction of the experimental materials were displayed with better DNA 153 quality for following SSR-PCR analysis (Figure 1). The amplification effects were obviously different in the orthogonal designed SSR-PCR reaction system (16 designs) (Figure 2, Table S2). The clear amplified bands were displayed in the designs No.1, 2, 6, 7, 10, 13 and 14, but designs 
155 No.3, 8 and 11 showed weak and small amount of amplified bands, designs No.4, 5, 9, 12,15 156 and 16 exhibited no bands. In this study we selected the design No.7 as the more appropriate one, 157 for which $10 \mu \mathrm{L}$ reaction volume containing template DNA $30 \mathrm{ng}$, dNTP $240 \mu \mathrm{mol} / \mathrm{L}, \mathrm{Mg}^{2+} 2.0$ $158 \mathrm{mmol} / \mathrm{L}$, SSR primer $1.5 \mu \mathrm{mol} / \mathrm{L}$, Taq enzyme $0.5 \mathrm{U}$. Then, the randomly selected 24 pairs of 159 primers were used to verify the stability of the system, and showed that all the primers could be 160 all amplified with polymorphic bands (Figure S1), indicating that this system could be used for 161 soybean genetic diversity of SSR markers.

162 True hybrid identification of different soybean cross

163 In this study, 18 pairs of SSR primers were randomly selected in the soybean 20 linkage 164 groups to screen the polymorphic SSR markers among 7 parents of 11 combinations of 165 backcrosses or three-way crosses (A-K). The numbers of parental polymorphic SSR primers 166 varied between 5 and 11 (Table S3), and two pairs of SSR primers (Satt682 and Satt440) were

167 168 169

170 located in $\mathrm{C}_{1}$ and I linkage groups, displayed co-dominant and parental polymorphism among all the parents (Figure S2). One of them, Satt682 was adopted to identify the true hybrids. For example, in Figure 3A, it showed that, the band 3 was the characteristic one of the female parent $\left(\mathrm{P}_{1}\right)$ and the band 4 for the male parent $\left(\mathrm{P}_{2}\right)$, with regard to the $26^{\text {th }}$ plant, the band 1 came from $\mathrm{P}_{1}$, band 2 from $\mathrm{P}_{2}$, and so we can determine that the $26^{\text {th }}$ plant is a true hybrid. Accordingly, 30 true hybrids (accounting for 14.1\%) were gained successfully from the harvested 213 single hybrid plants of 11 cross combinations, and partial combinations, such as A, B, C and G were displayed in Figure 3.

\section{Effects of salt stress on seedling salt tolerant coefficient and growth of the true hybrid lines} and their parents of cross combination $G$

The gained-above 6 true hybrid lines of cross combination G (G1, G3, G9, G12, G13 and G16) and their parents (Nannong 1138-2 and 3060) were used as the representative experimental materials to evaluate the salt tolerance. When the $1^{\text {st }}$ plants, $50 \%$ or $100 \%$ plants showed leaf salt injury symptoms, the salt tolerant coefficient of female parent Nannong 1138-2 was obviously lower than that of the male parent 3060. The salt tolerant coefficient of hybrid lines G1, G12, G13 and G16 was almost equal to Nannong 1138-2, but significantly lower than 3060 when 50\% or $100 \%$ plants showed leaf salt injury symptoms. However, the salt tolerant coefficient of hybrid lines G3 and G9, was roughly equal to the male parent 3060 at the above 3 different salt injury levels, and thus displayed their stronger salt tolerance, especially for G9 (Figure 4). 
186

187

188

189

190

191

192

193

194

195

196

197

198

199

200

201

202

203

204

205

206

207

208

209

210

211

212

213

214

215

216

Under $120 \mathrm{mmol} / \mathrm{L} \mathrm{NaCl}$ for 10 days, the relative growth rate of seedlings of the above true hybrid lines and their parents of cross combination $G$ all decreased evidently when compared with the control, the declines of hybrid lines G3 and G16 (33.3\% and 35.5\%, respectively) were equal to their male parent $3060(34.4 \%)$, but were significantly less than that of their female Nannong1138-2 (48.7\%). The decline of the hybrid line G9 (21.4\%) was the smallest, and showed significant difference with both parents (Nannong 1138-2 and 3060) (Figure 5A). With regard to the dry matter accumulation (expressed as the percentage), the true hybrid lines and their parents all exhibited obvious drop under $\mathrm{NaCl}$ stress. Thereinto, hybrid lines $\mathrm{G} 9$ and $\mathrm{G} 13$ displayed the least drop (16.2\% and $18.2 \%$, respectively), and showed no significant difference with both parents (Nannong 1138-2 and 3060) (18.4\% and 23.0\%, respectively). As followed was the hybrid line G3 (drop of $27.1 \%$ ), its dry matter accumulation under salt stress was slightly lower than the two parents (Figure 5B).

\section{DISCUSSION}

Determining genetic purity of the hybrids is crucial to ensure reproducible breeding programs. The purity of the hybrid crops can be identified via traditional phenotypic character or through modern molecular marker-assisted selection. The former, which is relied on the different phenotypic traits of hybrids and their parental lines, is considerably restricted for the limited intuitive agronomical traits, or because some agronomical traits can be detected only in the particular plant growth period, and some traits are very vulnerable to the environmental conditions. The assessment of genetic purity of hybrids via molecular fingerprinting or banding patterns of their parental lines based on SSR markers have been utilized in some crops, such as in maize (Hipi et al., 2013), rice (Bora et al. 2016), and barley (Ben Romdhane et al., 2018). In our present study, the similar banding patterns (Figure 3) as Ben Romdhane et al. (2018) were observed in the true hybrids, which are co-dominant SSR markers from both parents. However, the banding patterns of the false hybrids were only displayed in either female parent $\left(\mathrm{P}_{1}\right)$ (Figure 3A, the No. 21 plant) or male parent (P2) (Figure 3A, the No.28 plant), even no parental bands appeared (Figure 3A, the No. 2 plant). The false hybrids may be due to unsuccessful hybridization, impure male parent and/or under an incompletely isolated pollination resulting in no parental pollen infiltration, and so on (Ben Romdhane et al., 2018).Thus, 30 true hybrids (accounting for 14.1\%) were successfully obtained from the harvested 213 single hybrid plants of the designed 11 cross combinations, but a large difference of the proportion of true hybrid was 
217 exhibited in different cross combinations. In cross combinations $\mathrm{A}, \mathrm{B}, \mathrm{C}, \mathrm{G}$ and $\mathrm{K}$, the 218 proportions of true hybrid were all more than $20 \%$, but zero was showed in cross combinations 219 D, E, F and J (Table 2). For example, there were 7 true hybrids (C2, C3, C9, C10, C12, C13 and $220 \mathrm{C} 14$ ) in the combination $\mathrm{C}$ with a relatively higher proportion (accounting for $36.8 \%$ of its 221 hybrids), following by cross combination $\mathrm{G}$ with 6 true hybrids (G1, G3, G9, G12, G13 and G16 222 lines, accounting for 30.0\%) (Table 2; Figure 3C, G).

223 The seedlings salt tolerant coefficient is often used as an important parameter to evaluate the 224 salt tolerance of soybean, higher value indicating stronger salt tolerance (Li et al., 2012). Our 225 results indicate that the salt tolerant coefficient of hybrid lines G3 and G9 was roughly equal to 226 their male parent 3060 at three different salt injury levels, and thus displayed their stronger salt 227 tolerance (Figure 4). With regard to the dry matter accumulation, hybrid lines G9 and G13 228 displayed the least drop (16.2\% and 18.2\%, respectively), but showed no significant difference 229 with the male parent 3060 and female parent Nannong1138-2 (23.0\% and 18.4\%, respectively). 230 Incorporation of salt tolerant genes into elite material can be done with traditional hybridization 231 in crosses between $G$. max cultivars and G. soja accessions or among G. max accessions, and if 232 combined with the modern molecular breeding techniques, such as the molecular SSR markers, 233 the true hybrids with excellent traits (e.g. salt tolerance) will be possible to obtain in a shorter 234 time (Lenis et al., 2011; Patil et al.,2016), and it will greatly benefit soybean breeders in the 235 development of salt-tolerant cultivars.

\section{CONCLUSIONS}

237 In this study, the true or false soybean hybrids of backcrosses or three-way crosses of $G$. $\max$ 238 and $G$. soja could be identified rapidly with the parental co-dominant SSR markers at the 239 molecular level, and 30 true hybrids (accounting for 14.1\%) were obtained among 213 single 240 plants of 11 cross combinations. The salt tolerance of 6 true hybrids (G1, G3, G9, G12, G13 and 241 G16) of cross combination $G$ and their parents was evaluated with parameters including the salt 242 tolerance coefficient, relative growth rate and dry matter accumulation, of them hybrids G9 243 displayed stronger salt tolerance, and could be further used as the excellent materials for 244 breeding new salt tolerant soybean cultivars. Thus, SSR marker technology can be a powerful 245 tool for identifying true hybrids of soybean, and together with the simple assay of salt tolerance parameters, it can be of great significance in breeding of new salt tolerant soybean cultivars. 


\section{REFERENCES}

249 Adisa RS, Balogun KS. 2013. Impact of improved technologies on small-scale soybean 250 production: empirical evidence from Benue State, Nigeria. Pakistan Journal of Agricultural 251

252 253 254

255

256

257

258

259

260

261

262

263

264

265

266

267

268

269

270

271

272

273

274

275

276

277 Sciences 50:305-310.

Ashraf M, Foolad MR. 2013. Crop breeding for salt tolerance in the era of molecular markers and marker-assisted selection. Plant Breeding 132:10-20.

Ben Romdhane M, Riahi L, Jardak R, Ghorbel A, Zoghlami N. 2018. Fingerprinting and genetic purity assessment of F1 barley hybrids and their salt-tolerant parental lines using nSSR molecular markers. 3 Biotech 8:57-65.

Bhatnagar-Mathur P, Vadez V, Sharma K. 2008. Transgenic approaches for abiotic stress tolerance in plants retrospect and prospects. Plant Cell Reports 27: 411-424.

Bora A, Choudhury PR, Pande V, Mandal AB. 2016. Assessment of genetic purity in rice (Oryza sativa L.) hybrids using microsatellite markers. 3 Biotech 6: 50-56.

Burnham KD, Francis DM, Dorrance AE, Fioritto RJ, St Martin SK. 2002. Genetic diversity patterns among phytophthora resistant soybean plant introductions based on SSR markers. Crop Science 42: 338-343.

Chinnusamy V, Jagendorf A, Zhu JK. 2005. Understanding and improving salt tolerance in plants. Crop Science 45:437-448.

Dawson DA, Ball AD, Spurgin LG, Martín-Gálvez D, Stewart IRK, Horsburgh GJ, Burke T. 2013. High-utility conserved avian microsatellite markers enable parentage and population studies across a wide range of species. BMC Genomics 14:176.

Du LL, Yu BJ. 2010. Analysis of salt tolerance, agronomic traits and seed quality of Glycine max, salt-born Glycine soja and their hybrids. Chinese Journal of Oil Crop Sciences 32: 077-082.

Gaitán-Solís E, Duque MC, Edwards KJ, Tohme J. 2002. Microsatellite repeats in common bean (Phaseolus vulgaris): isolation, characterization, and cross-species amplification in Phaseolus ssp. Crop Science 42: 2128-2136.

Hipi A, Surahman M, Ilyas S, Giyanto. 2013. Seed genetic purity assessment of maize hybrid using microsatellite markers. International Journal of Applied Science and Technology 3: $66-71$. 
278 Hyten D, Song Q, Zhu U, Choi IY, Nelson RL, Costa JM, Specht JE. 2006. Impacts of genetic 279 bottlenecks on soybean genome diversity. Proceedings of the National Academy of Sciences 280

281

282

283

284

285

286

287

288

289

290

291

292

293

294

295

296

297

298

299

300

301

302

303

304

305

306

307

308 of the United States of America 103:16666-16671.

Kim E, Hwang S, Lee I. 2017. SoyNet: a database of co-functional networks for soybean Glycine max. Nucleic Acids Research 45:D1082-D1089.

Kuroda Y, Tomooka N, Kaga A, Wanigadeva SMSW, Vaughan DA. 2009. Genetic diversity of wild soybean (Glycine soja Sieb. et Zucc.) and Japanese cultivated soybeans [G. $\max$ (L.) Merr.] based on microsatellite (SSR) analysis and the selection of a core collection. Genetic Resources \& Crop Evolution 56:1045-1055.

Lee GJ, Boerma HR, Villagarcia MR, Zhou X, Jr TEC, Li Z, Gibbs MO. 2004. A major QTL conditioning salt tolerance in s-100 soybean and descendent cultivars. Theoretical Applied Genetics 109(8):1610-1619.

Lee JD, Shannon JG, Vuong TD, Nguyen HT. 2009. Inheritance of salt tolerance in wild soybean (Glycine soja Sieb. and Zucc.) accession PI483463. Journal of Heredity 100:798-801.

Li F, Tian F, Zhang XK, Yu BJ. 2012. Analysis of seedlings salt tolerance of backcross hybrids of Glycine max and Glycine soja. Soybean Science 31:593-597.

Luo Q, Yu B, Liu Y. 2005. Differential sensitivity to chloride and sodium ions in seedlings of $G$. max and G. soja under NaCl stress. Journal of Plant Physiology 162:1003-1012.

Machado RUA, Serralheiro RP. 2017. Soil salinity: effect on vegetable crop growth. Management practices to prevent and mitigate soil salinization. Horticulturae 3:30-41.

Munns R, Tester M. 2008. Mechanisms of salinity tolerance. Annual Review of Plant Biology 59: 651-681.

Nandakumar N, Singh AK, Sharma RK, Mohapatra T, Prabhu KV, Zaman FU. 2004. Molecular finger-printing of hybrids and assessment of genetic purity of hybrid seeds in rice using microsatellite markers. Euphytica 136:257-264.

Patil G, Do T, Vuong TD, Valliyodan B, Lee JD, Chaudhary J, Shannon JG, Nguyen HT. 2016. Genomic-assisted haplotype analysis and the development of high-throughput SNP markers for salinity tolerance in soybean. Scientific Reports 6:19199.

Shrivastava P, Kumar R. 2015. Soil salinity: A serious environmental issue and plant growth promoting bacteria as one of the tools for its alleviation. Saudi Journal of Biological Sciences 22:123-131. 
309 Siew GY, Ng WL, Tan SW, Alitheen NB, Tan SG, Yeap SK. 2018. Genetic variation and DNA 310 fingerprinting of durian types in Malaysia using simple sequence repeat (SSR) markers. 311 Peerj 6: e4266-4279.

312 Tuler AC, Carrijo TT, Nóia LR, Ferreira A, Peixoto AL, da Silva Ferreira MF. 2015. SSR 313 markers: a tool for species identification in psidium (Myrtaceae). Molecular Biology 314 Reports 42:1501-1513.

315 Tuyen DD, Lal SK, Xu DH.2010. Identifcation of a major QTL allele from wild soybean 316 (Glycine soja Sieb. \& Zucc.) for increasing alkaline salt tolerance in soybean. Theoretical \& $317 \quad$ Applied Genetics 121:229-236.

318 Wang CM, Yasui H, Yoshimura A, Chang-Chao SU, Zhai HQ, Wan JM. 2003. Green rice 319 leafhopper resistance gene transferring through backcrossing and CAPS marker assisted 320 selection. Agricultural Science in China 2: 8-12.

$321 \mathrm{Wu} \mathrm{YB}, \mathrm{Yu}$ BJ. 2009. Gene expression of $\mathrm{Cl}^{-}$channel and its relation to chloride tolerance of 322 Glycine max, Glycine soja and their hybrid seedlings. Journal of Nanjing Agricultural $323 \quad$ University 32:67-71.

324 Yang TT, Mu LQ, Wang J. 2007. Optimizing SSR-PCR system of Panax ginseng by orthogonal 325 design. Journal of Forestry Research 18:31-34.

326 Yashitola J, Thirumurugan T, Sundaram RM, Naseerullah MK, Ramesha MS, Sarma NP, 327 Ramesh VS. 2002. Assessment of purity of rice hybrids using microsatellite and STS 328 markers. Crop Science 42:1369-1373.

329 Zhang XK, Zhou QH, Cao JH, Yu BJ. 2011. Differential Cl-/salt tolerance and NaCl-induced 330 alternations of tissue and cellular ion fluxes in Glycine max, Glycine soja and their hybrid 331 seedlings. Journal of Agronomy \& Crop Science 197:329-339. 


\section{Table 1 (on next page)}

The 11 soybean cross combinations used in this study 
Table 1 The 11 soybean cross combinations used in this study

\begin{tabular}{cc}
\hline Soybean cross combinations & Female $\times$ Male \\
\hline A & Lee68 $\times 4076$ \\
B & Lee $68 \times 4111$ \\
C & Lee68 $\times 3060$ \\
D & Lee68 $\times 185$ \\
E & Nannong $1138-2 \times 4076$ \\
F & Nannong $1138-2 \times 4111$ \\
G & Nannong $1138-2 \times 3060$ \\
H & Nannong $1138-2 \times 185$ \\
I & Nannong $8831 \times 4076$ \\
J & Nannong $8831 \times 4111$ \\
K & Nannong $8831 \times 3060$ \\
\hline
\end{tabular}

2 


\section{Table 2 (on next page)}

Results of molecular appraisal of 213 single hybrid seedlings of different soybean cross combinations with SSR marker Satt682 
1 Table 2 Results of molecular appraisal of 213 single hybrid seedlings of different soybean cross combinations 2 with SSR marker Satt682

\begin{tabular}{|c|c|c|c|}
\hline $\begin{array}{l}\text { Cross } \\
\text { combinations }\end{array}$ & $\begin{array}{l}\text { Total number of } \\
\text { hybrids }\end{array}$ & Number of pure hybrids & $\begin{array}{l}\text { Proportion of pure } \\
\text { hybrids (\%) }\end{array}$ \\
\hline A & 28 & $8(\mathrm{~A} 3, \mathrm{~A} 7, \mathrm{~A} 10, \mathrm{~A} 16, \mathrm{~A} 20, \mathrm{~A} 23, \mathrm{~A} 25, \mathrm{~A} 26)$ & 28.6 \\
\hline B & 14 & 4 (B6, B7, B8, B9) & 28.6 \\
\hline $\mathrm{C}$ & 19 & 7 (C2, C3, C9, C10, C12、C13, C14) & 36.8 \\
\hline $\mathrm{D}$ & 12 & 0 & 0 \\
\hline E & 20 & 0 & 0 \\
\hline $\mathrm{F}$ & 20 & 0 & 0 \\
\hline G & 20 & $6(\mathrm{G} 1, \mathrm{G} 3, \mathrm{G} 9, \mathrm{G} 12, \mathrm{G} 13, \mathrm{G} 16)$ & 30.0 \\
\hline $\mathrm{H}$ & 20 & 0 & 0 \\
\hline $\mathrm{I}$ & 20 & 1 (19) & 5.0 \\
\hline $\mathrm{J}$ & 20 & 0 & 0 \\
\hline $\mathrm{K}$ & 20 & $4(\mathrm{~K} 13, \mathrm{~K} 14, \mathrm{~K} 15, \mathrm{~K} 16)$ & 20.0 \\
\hline Total & 213 & 30 & 14.1 \\
\hline
\end{tabular}




\section{Figure 1}

DNA extracted from leaves of soybean seedlings

Note: 1-7 DNA extracted from leaves (left to right) of parent Lee68 Nannong1138-2, Nannong8831, $4076\left(\mathrm{~F}_{5}\right), 4111\left(\mathrm{~F}_{5}\right], 3060 \square_{5}\left[\mathrm{~F}, 185 \square_{5}[\mathrm{~F} ; \mathrm{M}\right.$ : DNA marker.

*Note: Auto Gamma Correction was used for the image. This only affects the reviewing manuscript. See original source image if needed for review.

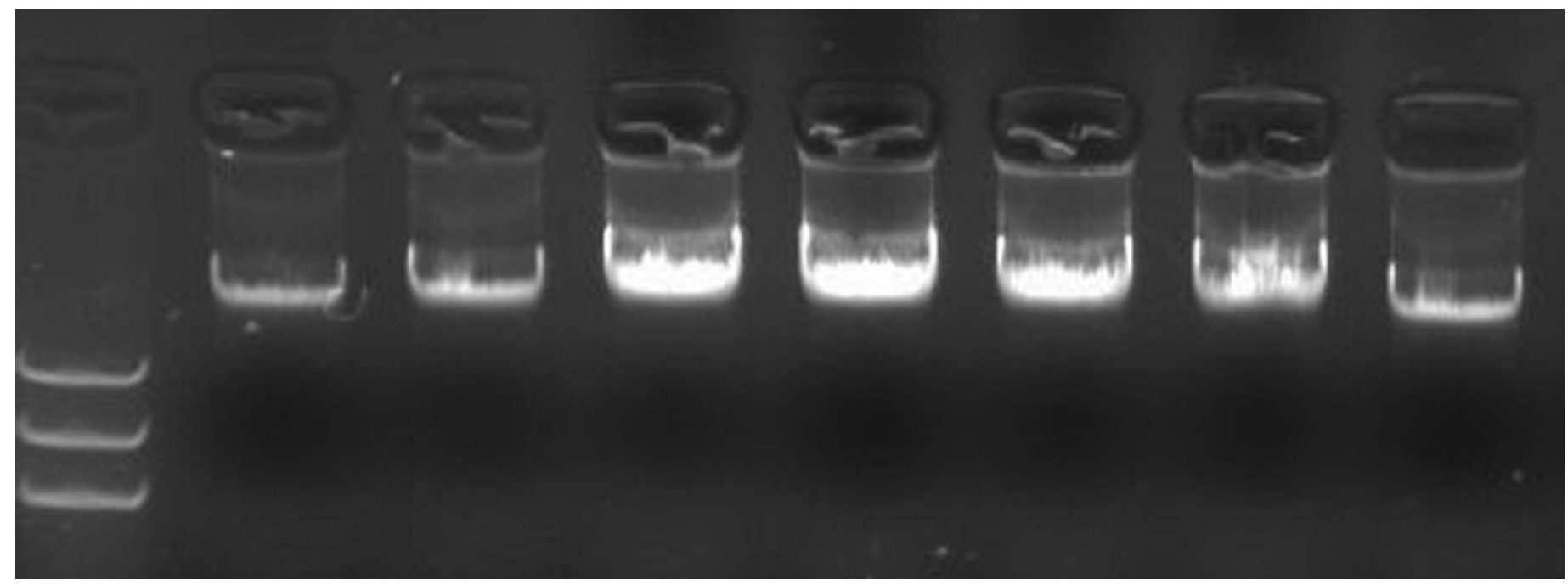




\section{Figure 2}

The amplified results of 16 designs according to the orthogonal design scheme

Note: 1-16, designs No.1-16 denoted in Supplementary Table 2; M. DNA marker; the used primer is Satt242. Observed bands in lane 7 were marked with arrows.
$\begin{array}{llllllllllllllllll}M & 1 & 2 & 3 & 4 & 5 & 6 & 7 & 8 & 9 & 10 & 11 & 12 & 13 & 14 & 15 & 16\end{array}$

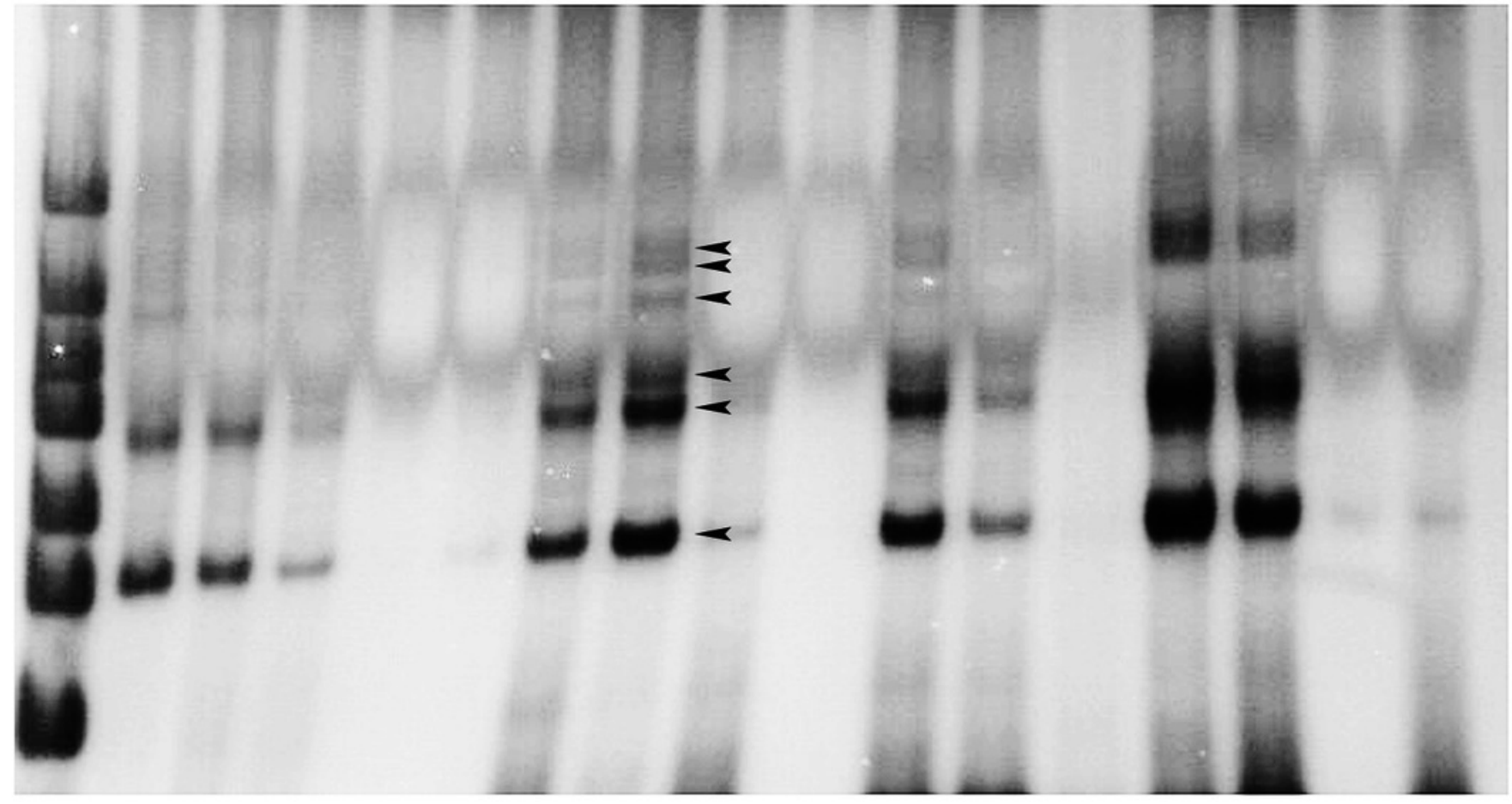




\section{Figure 3}

Gel electrophoresis assay of soybean hybrid lines and their parents using SSR marker Satt682

Note: (A) Gel electrophoresis of combination A, (B) Gel electrophoresis of combination B, (C) Gel electrophoresis of combination C, (D) Gel electrophoresis of combination G. The numbers are for the samples of the corresponding cross combination lines. $P_{1}$ : the corresponding combination female parents, $\mathrm{P}_{2}$ : the corresponding combination male parents, $\mathrm{M}$ : DNA marker; the labeled 1, 2, 3 and 4 in Figure A amplified respectively the bands of the $26^{\text {th }}$ plant and its parents. Observed bands from the parental lines were marked with arrows. 

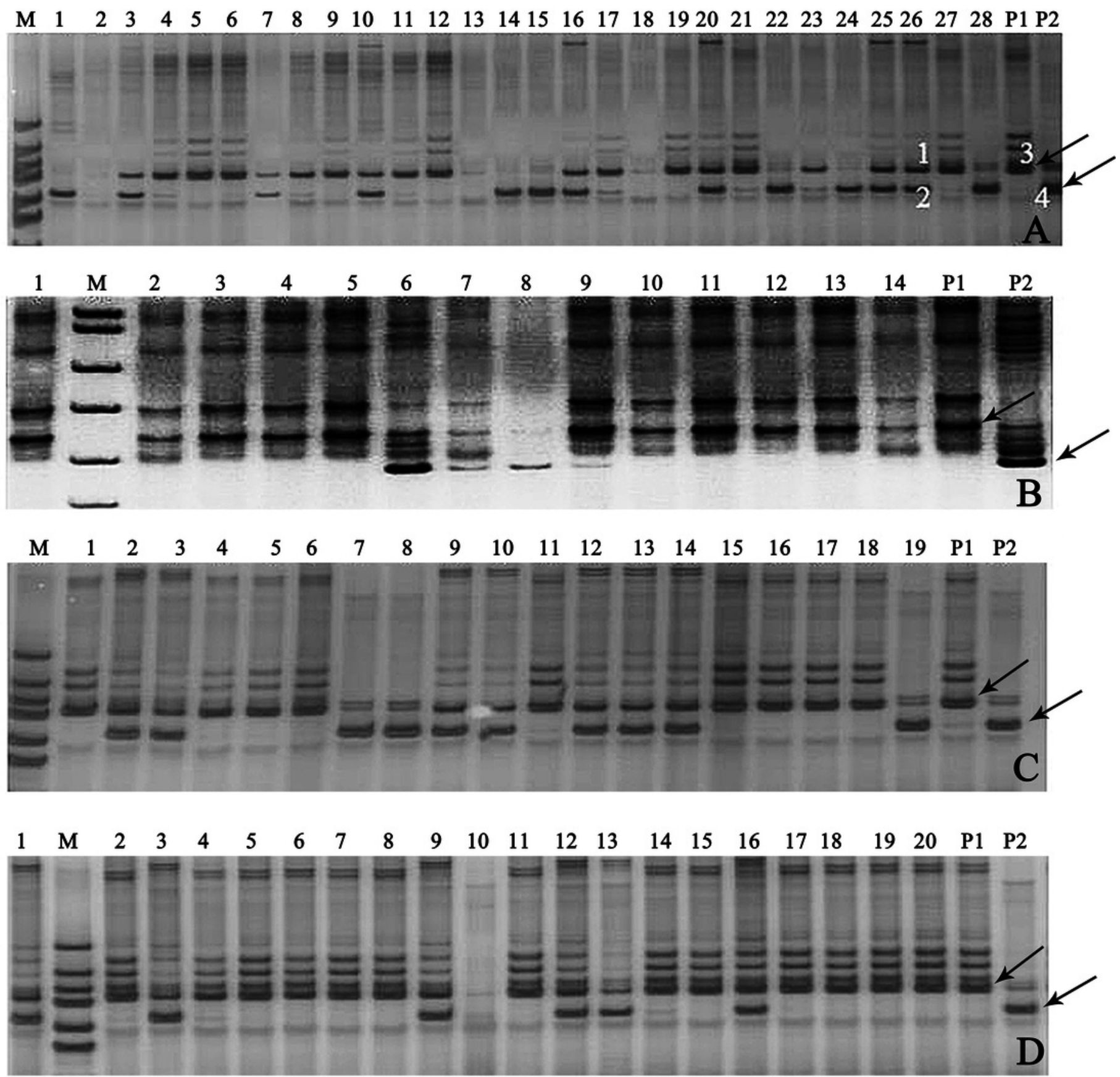


\section{Figure 4}

Comparison of salt tolerant coefficient in the hybrid lines and their parents of cross combination $\mathrm{G}$

Note: The $1^{\text {st }}$ plant: salt tolerant coefficient was calculated when the leaf salt injury symptom appeared on the $1^{\text {st }}$ plant seedling; the $50 \%$ plants: salt tolerant coefficient was calculated when the leaf salt injury symptom appeared on the $50 \%$ plant seedlings; the $100 \%$ plants: salt tolerant coefficient was calculated when the leaf salt injury symptom appeared on the $100 \%$ plant seedlings. The different lower case letters indicate significance $(P \square 0.05)$ for each state (the $1^{\text {st }}$ or $50 \%$ or $100 \%$ plants).

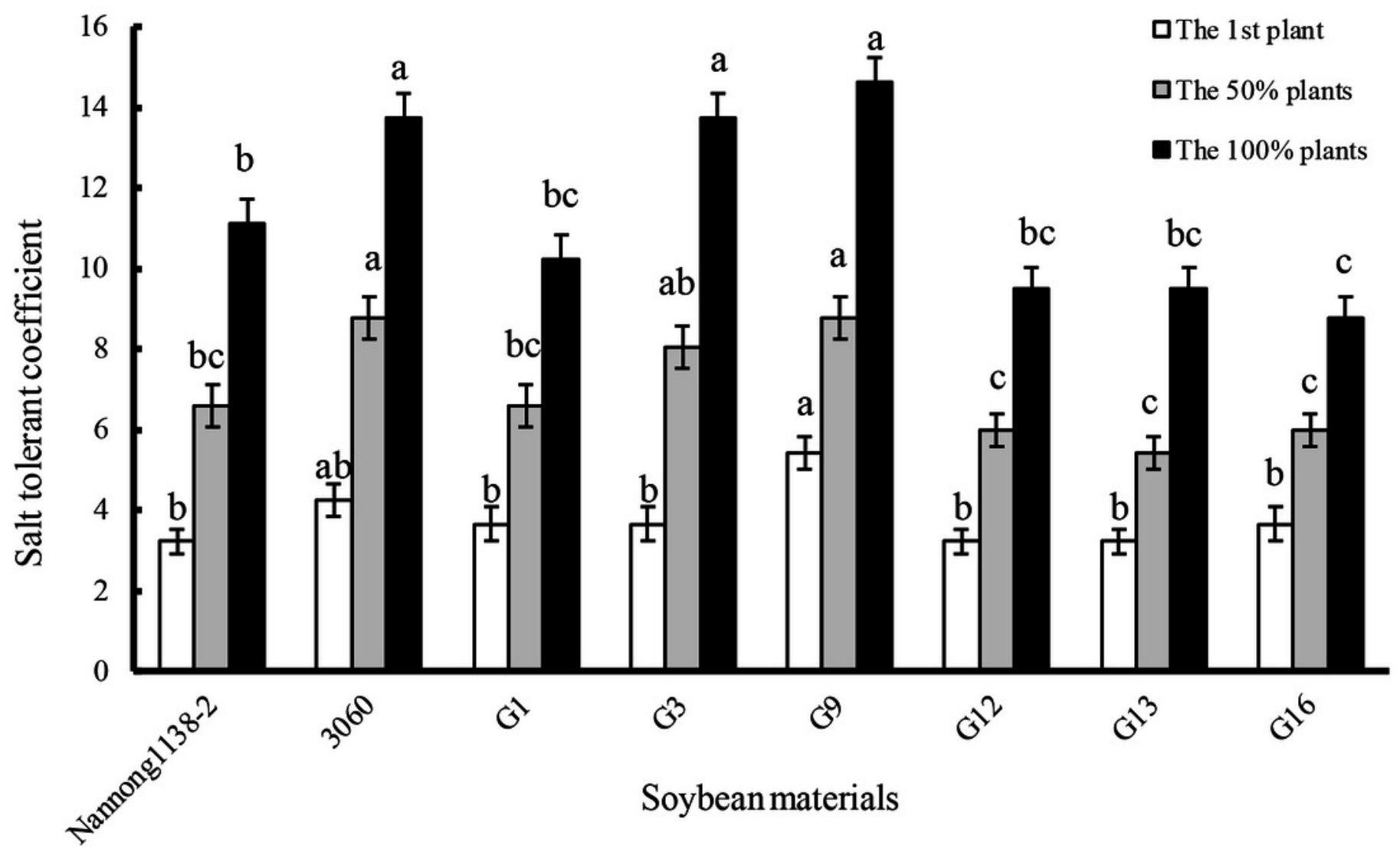


Figure 5

Changes in the relative growth rate (A) and dry matter accumulation (B) of hybrid seedlings of cross combination $\mathrm{G}$ and their parents under $120 \mathrm{mmol} / \mathrm{L} \mathrm{NaCl}$ for 10 days

Note: The different lower case letters indicate significance $(P \square 0.05)$. 

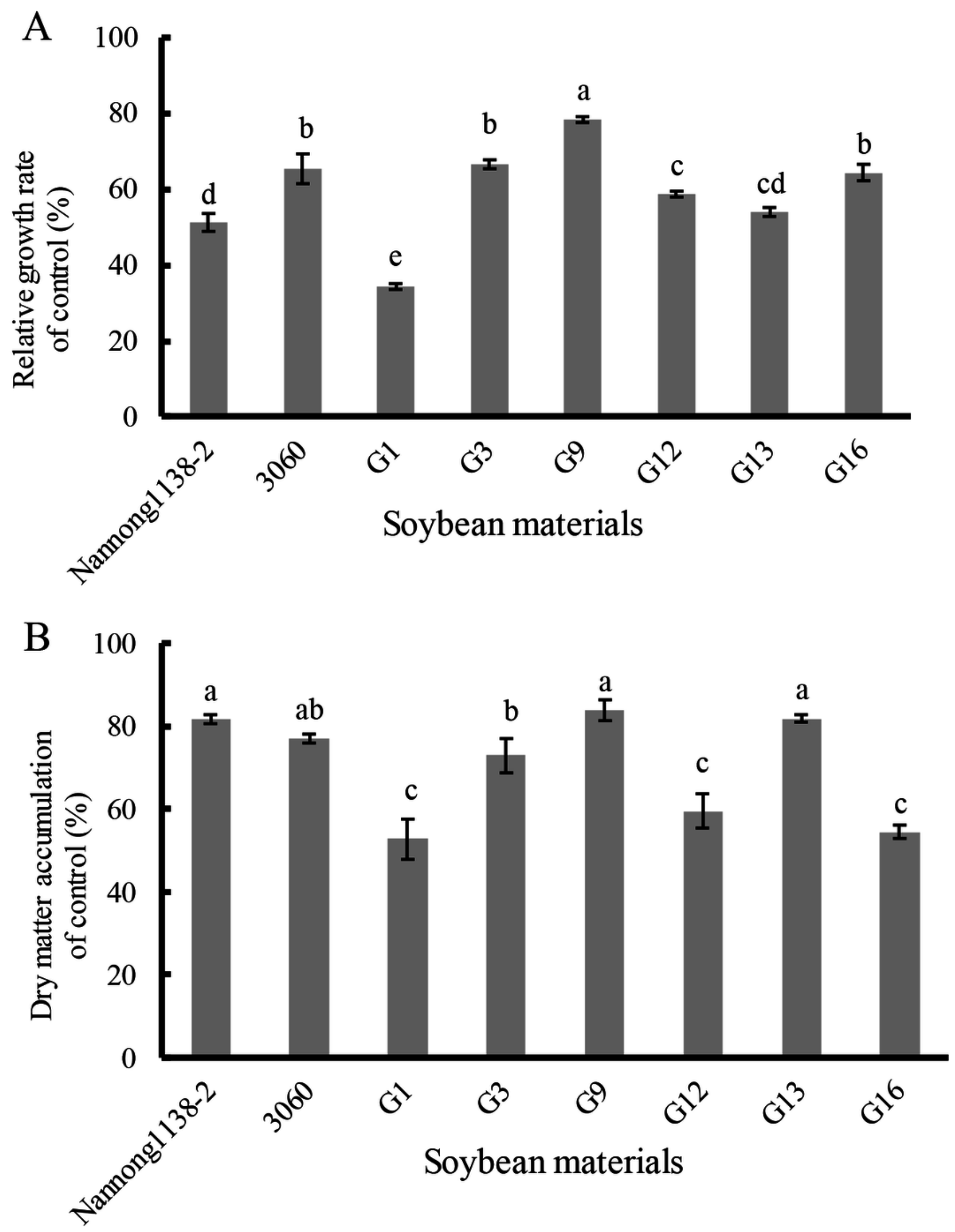